\title{
Hydration or dehydration: competing effects of upper tropospheric cloud radiation on the TTL water vapor
}

\author{
L. Wu ${ }^{1,2}$, H. Su ${ }^{1}$, J. H. Jiang ${ }^{1}$, and W. G. Read ${ }^{1}$ \\ ${ }^{1}$ Jet Propulsion Laboratory, California Institute of Technology, Pasadena, California \\ ${ }^{2}$ Joint Institute for Regional Earth System Science and Engineering, University of California, Los Angeles, California, USA
}

Correspondence to: L. Wu (longtao.wu@jpl.nasa.gov)

Received: 14 December 2011 - Published in Atmos. Chem. Phys. Discuss.: 8 February 2012

Revised: 3 July 2012 - Accepted: 21 August 2012 - Published: 28 August 2012

\begin{abstract}
A tropical channel version of the Weather Research and Forecasting (WRF) model is used to investigate the radiative impacts of upper tropospheric clouds on water vapor in the tropical tropopause layer (TTL). The WRF simulations of cloud radiative effects and water vapor in the upper troposphere and lower stratosphere show reasonable agreement with observations, including approximate reproduction of the water vapor "tape recorder" signal. By turning on and off the upper tropospheric cloud radiative effect (UTCRE) above $200 \mathrm{hPa}$, we find that UTCRE induces a warming of $0.76 \mathrm{~K}$ and a moistening of $9 \%$ in the upper troposphere at $215 \mathrm{hPa}$. However, UTCRE cools and dehydrates the TTL, with a cooling of $0.82 \mathrm{~K}$ and a dehydration of $16 \%$ at $100 \mathrm{hPa}$. The enhanced vertical ascent due to UTCRE contributes substantially to mass transport and the dehydration in the TTL. The hydration due to the enhanced vertical transport is counteracted by the dehydration from adiabatic cooling associated with the enhanced vertical motion. UTCRE also substantially changes the horizontal winds in the TTL, resulting in shifts of the strongest dehydration away from the lowest temperature anomalies in the TTL. UTCRE increases in-situ cloud formation in the TTL. A seasonal variation is shown in the simulated UTCRE, with stronger impact in the moist phase from June to November than in the dry phase from December to May.
\end{abstract}

\section{Introduction}

Water vapor in the stratosphere plays an important role in the stratospheric radiative budget and chemistry (e.g. Fueglistaler et al., 2009, and references therein). It is widely accepted that the entry of water vapor into the stratosphere is primarily regulated by the interaction of mass transport and dehydration in the tropics. However, considerable uncertainty exists about the details of water vapor entry from the tropical tropopause layer (TTL), the transition layer from the troposphere to the stratosphere.

It is suggested that air is transported to the stratosphere by large-scale slow vertical motions associated with clear-sky radiative heating (e.g., Brewer, 1949). Nonetheless, the mass flux associated with the clear sky radiative heating is too slow to support observational rate of troposphere-to-stratosphere transport (TST; e.g., Sherwood and Dessler, 2003). An alternative hypothesis is that the tropical TST is primarily contributed by deep convective overshooting (e.g., Sherwood and Dessler, 2000). Recently, the radiative effect of cirrus clouds is proposed to be a likely mechanism to accelerate the mass transport from the troposphere to the stratosphere (Corti et al., 2005; 2006; Huang and Su, 2008; Tzella and Legras, 2011).

Another debate exists because the entry of stratospheric water vapor is drier than the expected water vapor saturation mixing ratio with respect to zonal-mean temperature in the TTL (Newell and Gould-Stewart, 1981). Holton and Gettelman (2001) suggested that rapid horizontal advection will repeatly expose air to the lowest temperature region thereby dehydrating air to concentration lower than predicted by the tropical zonal mean temperature. Sherwood and Dessler (2000) postulated that dehydration might be primarily due to deep convective overshooting. However, experiments showed that overshooting convection hydrates rather than dehydrates the tropical lower stratosphere (e.g., Corti et al., 2008). Lagrangian trajectory calculations driven by 
synoptic-scale temperature and wind fileds from reanalysis data (Fueglistaler et al., 2005; Schoeberl and Dessler, 2011) can reproduce the entry of water vapor into the stratosphere well, validating the idea of Holton and Gettleman (2001). Due to the strong temperature dependence of water vapor pressure over ice, dehydration and transport are intrinsically coupled.

Previous studies have demonstrated that upper tropospheric cloud has significant radiative impacts on TTL temperature or mass transport. A single-layer thin cirrus in the TTL warms the local atmosphere by absorbing longwave radiation from surface but emitting at a lower temperature, and thus enhances vertical ascent. For multi-layer cirrus clouds, the cloud radiative effect (CRE) is dependent on the contrast of radiative fluxes between the cirrus in the TTL and underlying clouds (e.g., Hartmann et al., 2001). TTL cirrus overlapping thick clouds could radiatively cool the TTL and result in a weakening of vertical ascent. The opaque clouds $(\tau \geq 3$ ) can warm the TTL by absorbing solar radiation (Yang et al., 2010). Observational data show that cirrus leads to a net positive cloud radiative heating in the TTL (e.g., Su et al., 2009; Yang et al., 2010). With a two-dimension (2-D) model, Rosenfield et al. (1998) showed that the radiative heating of subvisible thin cirrus would result in a warming of $1-2 \mathrm{~K}$ and a vertical velocity increase of $0.02-0.04 \mathrm{~mm} \mathrm{~s}^{-1}$ in the TTL. The lower stratosphere is hydrated by as much as $1 \mathrm{ppmv}$ due to the warmer tropopause. However, other studies showed that cirrus radiative effects are complicated. On one hand, cirrus radiative heating drives the cloud lofting. The cirrus can persist for days and the TTL is dehydrated by the freezedrying process associated with the uplift of the cloud layer (Jensen et al., 1996; Jensen and Pfister, 2004). On the other hand, the cirrus radiative effects can dissipate clouds in several hours if the energy is only used to warm the atmosphere (Jensen et al., 1996). Dinh et al. (2010) suggested that radiative heating of subvisible cirrus has a potential to dehydrate the TTL by conversion of water vapor into ice through convergence of dry air, without involving adiabatic cooling associated with external large-scale uplift. Also, cirrus can be maintained by the circulation thermally forced by the cloud radiative heating.

Since most of the previous modeling studies were based on idealized 2-D framework, a realistic representation of 3D structure of the TTL is needed to better understand and quantify the radiative impacts of clouds on the TTL water vapor. Driven by reanalysis data, a 3-D tropical channel model is used in this study to investigate the radiative impacts of upper tropospheric (above $200 \mathrm{hPa}$ ) clouds on the TTL water vapor. The model configuration is described in Sect. 2. In Sect. 3, the performance of the tropical channel model in representing CRE and water vapor in the TTL is presented in comparison with satellite observations. Section 4 presents the upper tropospheric cloud radiative effects (UTCRE) on the TTL in the model. The physical processes related to the TTL hydration/dehydration by UTCRE are discussed in Sect. 5 . The conclusion is given in Sect. 6.

\section{Model configuration}

As a state-of-the-art atmospheric simulation system, the Weather Research and Forecasting (WRF) model is suitable for a broad range of applications across scales ranging from meters to thousands of kilometers. The Advanced Research WRF (ARW) model (Skamarock et al., 2008) Version 3.3 is used in this study. Different from the common practice that uses WRF with a regional domain, model simulations in this study are configured as a tropical channel model with global coverage in the zonal direction but tropically constrained boundaries in the meridional direction. The tropical channel configuration allows for a realistic depiction of tropical circulation in the UTLS as the horizontal transport of water vapor is quite important to understand the dehydration in the upper troposphere and lower stratosphere (UTLS). It has been shown that the tropical channel configuration can reproduce the initiation and gross features of Madden-Julian oscillation (MJO) events (Ray and Zhang, 2010; Ray et al., 2011).

The control simulation (referred to as CTRL) runs at $50 \mathrm{~km}$ horizontal resolution, covering $15^{\circ} \mathrm{S}$ to $45^{\circ} \mathrm{N}$ and $180^{\circ} \mathrm{W}$ to $180^{\circ} \mathrm{E}$. The meridional asymmetry is to avoid a deleterious feedback from a systematic high bias in the Southern Hemispheric (south to $15^{\circ} \mathrm{S}$ ) TTL water vapor, which appears to be related to poor representation of the stratospheric circulation in this version of WRF (Jiang et al., 2010). A periodic boundary condition is used in the east-west direction. The specified lateral boundary conditions in the north-south boundaries apply to the horizontal wind components, potential temperature, water vapor, geopotential and air mass, with a nine-point relaxation zone. The initialization fields and lateral boundary conditions (surface and northsouth boundaries) for meteorological fields are obtained from the T255 $(\sim 79 \mathrm{~km})$ horizontal resolution of ERA-Interim reanalysis data (http://dss.ucar.edu/datasets/ds627.0/), with an update at every 5 days (over the 5 days, an average tendency for every prognostic variable is imposed at every time step based on the differences between the 5 days) for the lateral boundary conditions. To minimize the impact of lateral boundary conditions, the simulated results within $10^{\circ} \mathrm{S}-40^{\circ} \mathrm{N}$ are analyzed with a focus on the inner tropics $\left(10^{\circ} \mathrm{S}-10^{\circ} \mathrm{N}\right)$, outside the relaxation zone at the northsouth boundary. The model simulation is conducted from 1 September 2004 to 30 November 2008. Analyses are focused on the last four years (1 December 2004 to 30 November 2008) to avoid the impact of initial conditions. With a terrain-following hydrostatic-pressure coordinate, the model top is set at $10 \mathrm{hPa}$. The model has 49 vertical levels in a terrain-following hydrostatic-pressure vertical coordinate, including 7-8 levels in the TTL, with the vertical resolution of $\sim 0.6 \mathrm{~km}$. Based on the observed large-scale dynamical 
structures, Fueglistaler et al. (2009) defined the TTL as a layer between $150 \mathrm{hPa}(\sim 14 \mathrm{~km})$ and $70 \mathrm{hPa}(\sim 18.5 \mathrm{~km})$. In this study, we follow their definition of the TTL, focusing on the 5 pressure levels $(147 \mathrm{hPa}, 121 \mathrm{hPa}, 100 \mathrm{hPa}, 83 \mathrm{hPa}$ and $68 \mathrm{hPa}$ ) in the TTL, which are the standard pressure levels for the Aura Microwave Limb Sounder (MLS) water vapor products. Model simulations are interpolated to the MLS standard pressure levels.

The principal physical schemes used in the simulation include the Lin et al. microphysics scheme (Chen and Sun, 2002), the Grell 3D ensemble cumulus scheme (Grell and Devenyi, 2002), the Rapid Radiative Transfer Model for Global climate models (RRTMG) longwave scheme (Mlawer et al., 1997; Iacono et al., 2000) and the Goddard shortwave scheme (Chou and Suarez, 1994). In the radiation parameterization, CRE is calculated as a function of diagnostic cloud fraction based on relative humidity. In order to investigate UTCRE, a sensitivity run (referred as to UTNR) is conducted by turning off CRE (both longwave and shortwave) above $200 \mathrm{hPa}$, with no modifications of cloud contents and other parameters. Thus, the differences between the CTRL and UTNR simulations represent UTCRE.

\section{Model performance}

The MLS Level 2 water vapor product V3.3 (Livesey et al., 2011) is used in this study to evaluate the WRF simulated water vapor in the TTL. Launched in July of 2004, the MLS instrument on board the Aura satellite provides global measurement of upper tropospheric and stratospheric water vapor (Waters et al., 2006). The MLS water vapor data in the TTL have a vertical resolution of $\sim 3 \mathrm{~km}$ and horizontal resolutions of $\sim 7 \mathrm{~km}$ across-track and $\sim 200 \mathrm{~km}$ along-track. The measurement uncertainties of water vapor in the TTL are about $4 \%$ to $15 \%$ (Read et al. 2007).

As the water vapor "tape recorder" (the imprint of tropical temperature on water vapor entering the stratosphere; Mote et al., 1996) clearly marks the seasonal cycle in tropical tropopause temperature coupled with vertical ascent, we first examine the simulated water vapor "tape recorder" in the WRF model. As shown in Fig. 1a, the MLS observed water vapor "tape recorder" shows dry anomalies in the first half of a year (from December to May, hereafter referred to as dry phase), and moist anomalies in the second half of a year (from June to November, hereafter referred to as moist phase). Water vapor is transported from $121 \mathrm{hPa}$ through the stratosphere while the water vapor signals imprinted at the bottom of the stratosphere are maintained for several months. The WRF CTRL simulation (Fig. 1b) captures seasonal variations of water vapor in the TTL, albeit with a smaller magnitude of the anomalies compared to the MLS data. However, the simulated water vapor "tape recorder" travels upward faster than the MLS observations, especially in the stratosphere. The simulated mean all-sky vertical velocity in

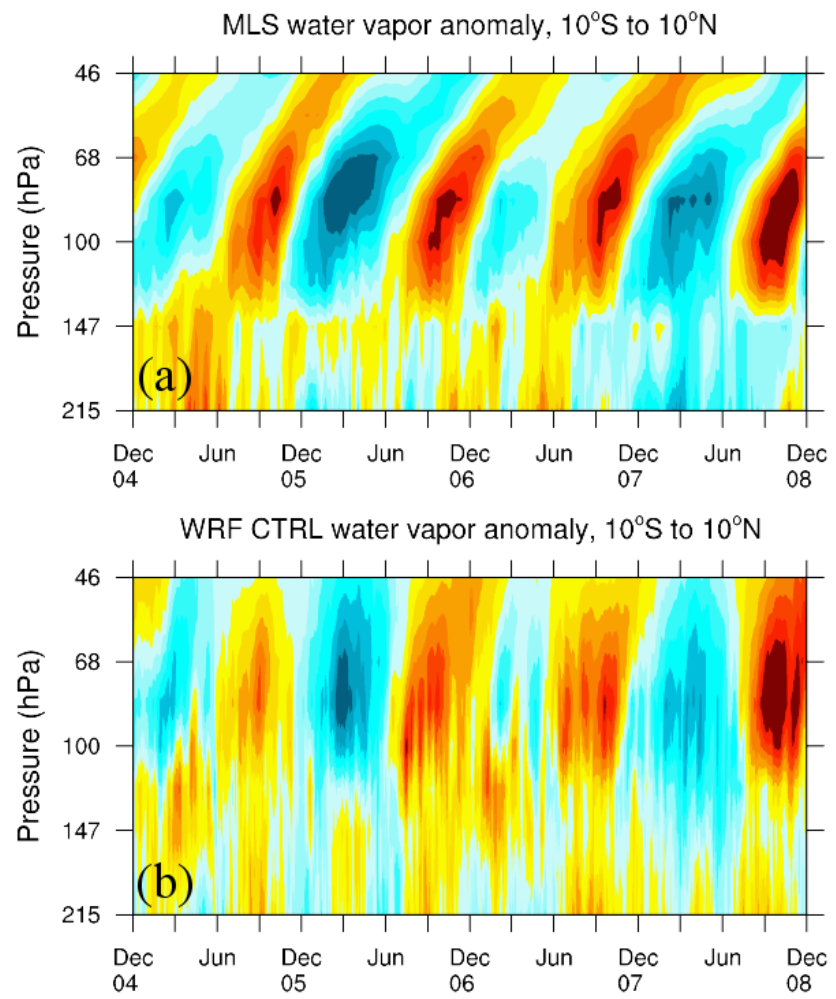

Fig. 1. Height-time cross section of inner tropical $\left(10^{\circ} \mathrm{S}-10^{\circ} \mathrm{N}\right)$ mean water vapor anomalies from (a) MLS and (b) the WRF CTRL run. The anomalies are relative to inner tropical mean averaged from 1 December 2004 to 30 November 2008.

the inner tropics is $0.67 \mathrm{~mm} \mathrm{~s}^{-1}$ at $100 \mathrm{hPa}$, somewhat larger than the observed mean vertical velocity about $0.4 \mathrm{~mm} \mathrm{~s}^{-1}$ (Mote et al., 1998).

The MLS water vapor spatial distribution at $100 \mathrm{hPa}$ (Fig. 2a) shows a minimum over the tropical western Pacific in December-January-February (DJF). In June-July-August (JJA), the tropical western Pacific and Indian Ocean are relatively dry while two moist regions are shown at mid-latitude over Asia and Central America (Fig. 2b). The WRF CTRL simulation in DJF (Fig. 2c) captures the location of $100 \mathrm{hPa}$ water vapor minimum in the western Pacific. However, the model simulation is drier than the MLS data over the relatively dry regions while it is moister over the relatively moist regions. The relative distributions of dry and moist regions in JJA are also captured in the model simulation (Fig. 2d). However, the dry regions over the tropical western Pacific and Indian Ocean shift westward while the moist regions at mid-latitude shift eastward, comparing to the MLS observations. Similar to in DJF, the simulated water vapor over relatively dry regions is drier than MLS, but moister over relatively moist regions in JJA. Averaged over the inner tropics, the MLS (WRF CTRL) water vapor at $100 \mathrm{hPa}$ is 3.29 (3.26) ppmv in DJF and 4.68 (3.88) ppmv in JJA. 

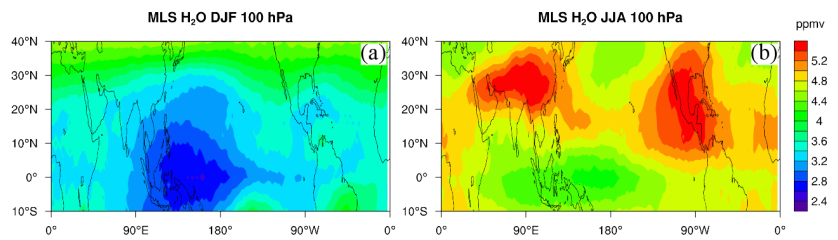

WRF CTRL QVAPOR DJF $100 \mathrm{hPa}$

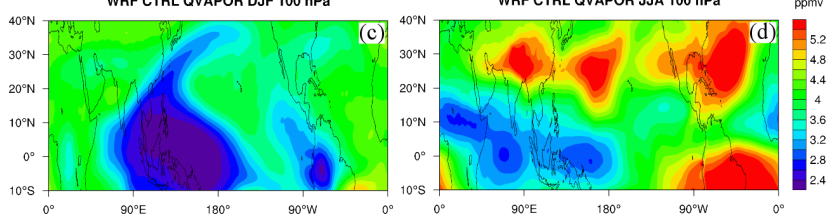

Fig. 2. 4-yr averaged water vapor (ppmv) at $100 \mathrm{hPa}$. (a) MLS in DJF; (b) MLS in JJA; (c) WRF CTRL in DJF; (d) WRF CTRL in JJA.

The Clouds and Earth's Radiant Energy System (CERES) Synoptic (SYN) product provides observed TOA (top of atmosphere) fluxes at $1^{\circ}$ spatial and 3 hourly temporal resolution. The difference of TOA fluxes between all-sky condition and clear-sky condition is referred as the cloud radiative forcing. As the clear-sky shortwave flux data contain a lot of missing values, we use only TOA longwave fluxes from the CERES Aqua SYN1deg-lite_Ed2.6 monthly product (http://ceres.larc.nasa.gov) and the derived longwave cloud forcing (LWCF).

Figure 3 compares the LWCF from the CERES data with the WRF CTRL simulations in DJF and JJA. The WRF simulations reproduce the LWCF distribution and seasonal variations observed by CERES. In DJF, the magnitude of the simulated LWCF (Fig. 3c) is generally smaller than the magnitude of the CERES observations (Fig. 3a). In JJA, the simulated LWCF (Fig. 3d) is smaller over land but larger over ocean, comparing to the CERES data (Fig. 3b). Averaged in the inner tropics, the CERES (WRF CTRL) LWCF is 38.67 (26.69) $\mathrm{W} \mathrm{m}^{-2}$ in DJF and 35.85 (32.42) $\mathrm{W} \mathrm{m}^{-2}$ in JJA.

Overall, the WRF model reasonably reproduces the relative distribution and seasonal variations of CRE and water vapor in the TTL, although the magnitude and location of simulated CRE and water vapor show discrepancies from observations.

\section{Radiative effects of upper tropospheric clouds}

Figure 4a shows the 4-yr averaged longwave (LW), shortwave (SW) and net (NET) radiative heating rates in the inner tropics $\left(10^{\circ} \mathrm{S}-10^{\circ} \mathrm{N}\right)$. For both the WRF CTRL and UTNR simulations, SW radiation warms in the UTLS while LW radiation warms the TTL but cools the upper troposphere (UT) from $215 \mathrm{hPa}$ to $147 \mathrm{hPa}$ and lower stratosphere above $68 \mathrm{hPa}$. In total, there is a radiative heating in the TTL and lower stratosphere, but a radiative cooling in the UT. UTCRE increases radiative heating rate in the UT by both SW and LW radiation (Fig. 4b). In the lower TTL between $147 \mathrm{hPa}$
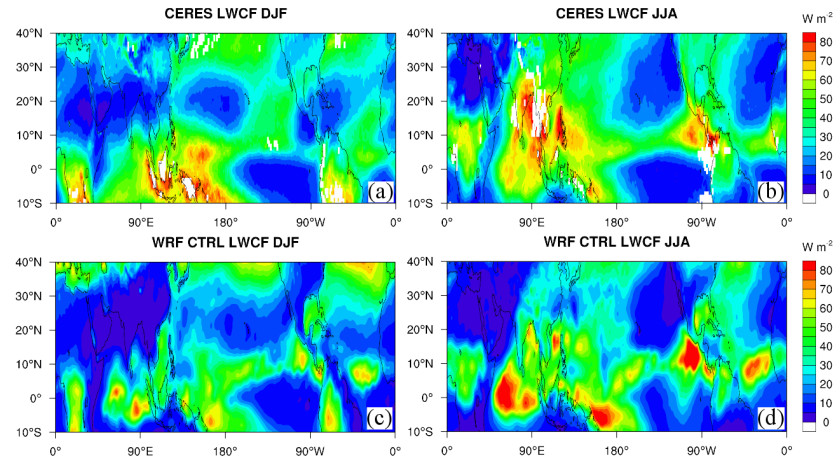

Fig. 3. 4-yr averaged LWCF $\left(\mathrm{W} \mathrm{m}^{-2}\right)$ at the TOA. (a) CERES in DJF; (b) CERES in JJA; (c) WRF CTRL in DJF; (d) WRF CTRL in JJA. White represents missing data in the CERES data.

and $83 \mathrm{hPa}$, UTCRE increases radiative heating rate by enhanced LW warming, but decreases radiative heating rate by reduced SW absorption. Above $83 \mathrm{hPa}$, UTCRE corresponds to increased LW cooling and little changes in SW fluxes.

Figure 5 shows the height-time cross section of the UTCRE induced differences averaged over the inner tropics. UTCRE warms and moistens the UT, but cools and dehydrates the TTL most of the time (Fig. 5a and b). Seasonal variations of the UTCRE induced changes are seen in the TTL water vapor, with more intense dehydration in the moist phase (from June to November) and moderate dehydration in the dry phase (from December to May). The cooling and dehydration in the dry phase also tends to extend higher in the vertical than in the moist phase. Due to the strong temperature dependence of the water vapor pressure over ice, the tropical-averaged moisture changes (Fig. 5a) follow the temperature changes (Fig. 5b) in the sign, but their magnitudes are not exactly in phase. For example, the maximum cooling occurs in the dry phase, not in the moist phase. Such shift in phase relation of tropical-averaged water vapor and temperature are results of inhomogeneous response to the UTCRE as discussed in section 5 . On the $4-y r$ average at $215 \mathrm{hPa}$, there is a warming of $0.76 \mathrm{~K}$ (maximum up to $1.28 \mathrm{~K}$ ) and a moistening of $9 \%$ (maximum up to $23 \%$ relative to the CTRL run). The warming and moistening gradually weaken with height in the UT. A transition layer from warming and hydration to cooling and dehydration is shown around $147 \mathrm{hPa}$. Maximum mean cooling and dehydration occur at $100 \mathrm{hPa}$ with an average cooling of $0.82 \mathrm{~K}$ (maximum cooling up to $1.97 \mathrm{~K}$ in the dry phase) and a dehydration of $16 \%$ (maximum dehydration up to $40 \%$ in the moist phase). Above $100 \mathrm{hPa}$, the cooling and dehydration gradually weaken with height.

UTCRE increases the vertical ascent between $215 \mathrm{hPa}$ and $121 \mathrm{hPa}$, with maximum increase of vertical velocity at $215 \mathrm{hPa}$ and intense (moderate) enhancement in the moist (dry) phase (Fig. 5c). On the 4-yr average, the increase of vertical velocity $\left(3.18 \mathrm{~mm} \mathrm{~s}^{-1}\right)$ by UTCRE is about $49 \%$ of 

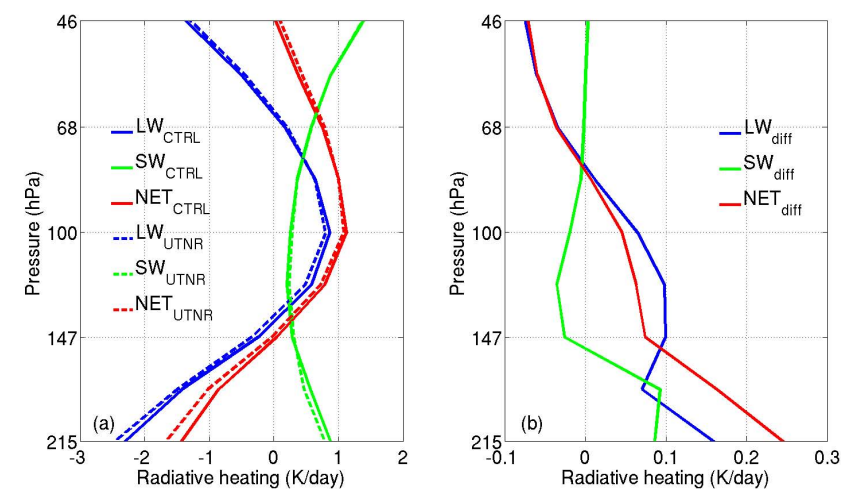

Fig. 4. (a) 4-yr averaged radiative heating rates $\left(\mathrm{K} \mathrm{day}^{-1}\right)$ in the inner tropics $\left(10^{\circ} \mathrm{S}-10^{\circ} \mathrm{N}\right)$. Solid (dashed) blue is $\mathrm{LW}$ radiative heating in the WRF CTRL (UTNR) run. Solid (dashed) green is SW radiative heating in the WRF CTRL (UTNR) run. Solid (dashed) red is the net (NET) of SW and LW radiative heating in the WRF CTRL (UTNR) run. (b) 4-yr averaged differences of radiative heating rates $\left(\mathrm{K} \mathrm{day}^{-1}\right)$ between the WRF CTRL and UTNR runs in the inner tropics for LW (blue), SW (green) and NET (red).

mean vertical velocity at $215 \mathrm{hPa}$ in the CTRL simulation $\left(6.50 \mathrm{~mm} \mathrm{~s}^{-1}\right)$. On the domain averages between $100 \mathrm{hPa}$ and $83 \mathrm{hPa}$, UTCRE increases vertical velocities in DJF, but decreases them in JJA (Fig. 5c and 6). The domain-averaged change of vertical velocity tends to extend higher in the dry phase, corresponding to the higher cooling and dehydration in the dry phase in the TTL. UTCRE results in slight subsidence above $83 \mathrm{hPa}$. For ice water content (IWC), UTCRE mainly increases clouds in the UT and lower TTL (Fig. 5d), especially in the moist phase, while it decreases clouds at some of the time around DJF.

\section{Discussion}

Based on the thermodynamic energy balance, a perturbation to diabatic heating in the TTL is expected to be balanced by adiabatic motion and temperature change. The 4-yr mean tropical-averaged changes in our simulations suggest that the increased radiative heating rate by UTCRE (Fig. 4b) induces both warming and ascent in the UT (Fig. 5b and 5c). The warming decreases the tendency of ice formation in the UT while the enhanced upwelling transports more moisture from below. The net is a moisture increase in the UT (Fig. 5a). Clouds also increase (Fig. 5d), probably related to enhanced vertical transport of ice particles and stronger convective updraft. From $147 \mathrm{hPa}$ to $121 \mathrm{hPa}$, relatively smaller radiative heating than the UT (Fig. 4b) associated with larger static stability causes weaker increase of ascent. The enhanced adiabatic cooling leads to temperature decrease in this layer of long radiative relaxation time scale. Moisture decreases in response to decreased temperature. Cloud increases (Fig. 5d) are contributed by both vertical transport and freeze-drying
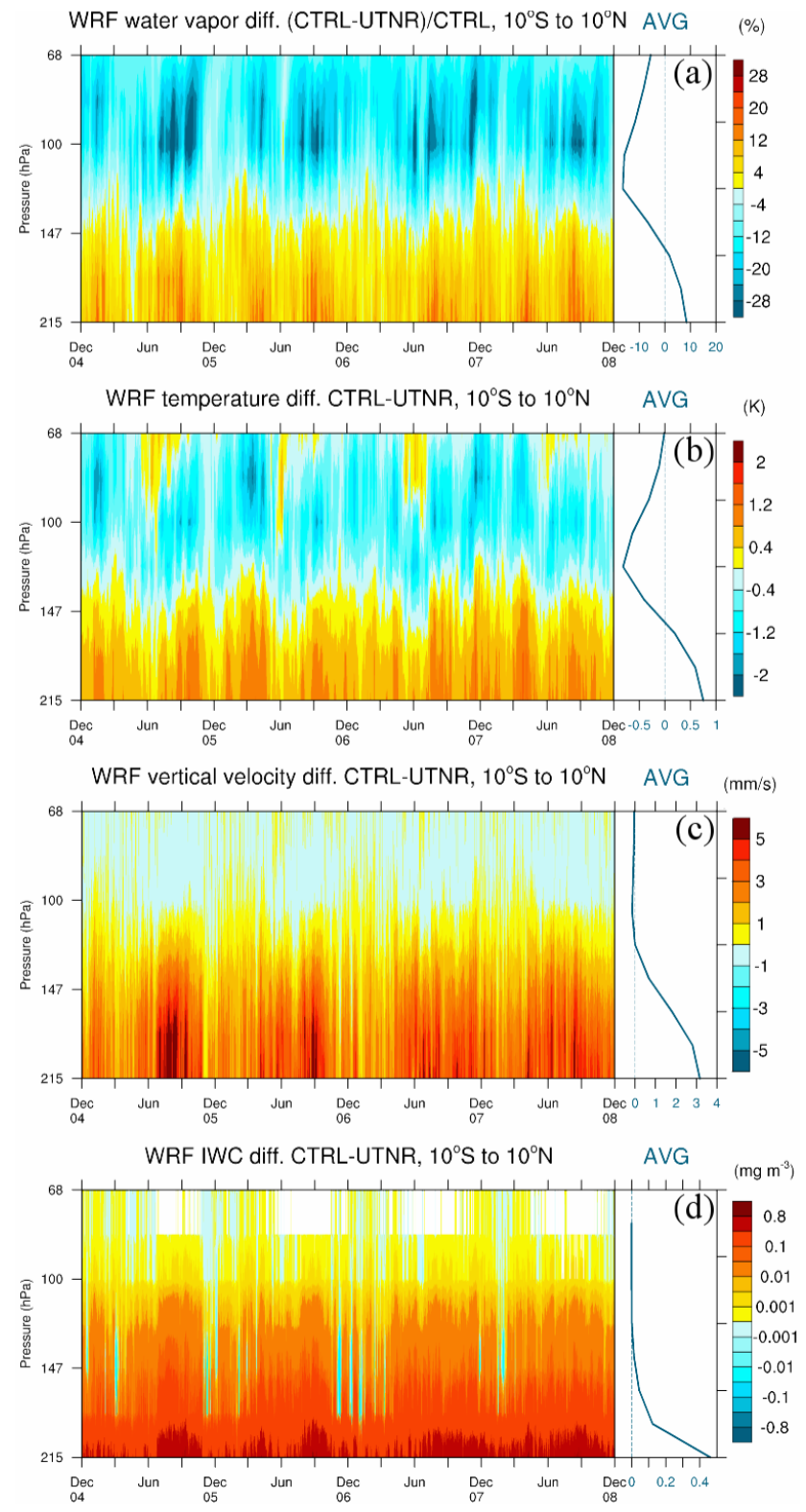

Fig. 5. (left panel) Height-time cross section of inner tropical $\left(10^{\circ} \mathrm{S}-10^{\circ} \mathrm{N}\right)$ mean daily differences between the WRF CTRL and UTNR simulations for (a) water vapor difference (\%) relative to the WRF CTRL run; (b) temperature difference $(\mathrm{K})$; (c) vertical velocity difference $\left(\mathrm{mm} \mathrm{s}^{-1}\right)$; (d) IWC difference $\left(\mathrm{mg} \mathrm{m}^{-3}\right)$. (right panel) Vertical profiles of 4-yr mean differences in left panel.

processes. Above $83 \mathrm{hPa}$, the decreased radiative heating rate by UTCRE (Fig. 4b) is balanced by slight decrease of vertical motion, which leads to cooling and continued dehydration (Fig. 5).

Detailed examination of the differences between the CTRL and UTNR runs at $100 \mathrm{hPa}$ and $83 \mathrm{hPa}$ indicates that there are significant departures from the aforementioned simple thermodynamic energy balance view. Considering the seasonal variations, as shown by the time series of the 


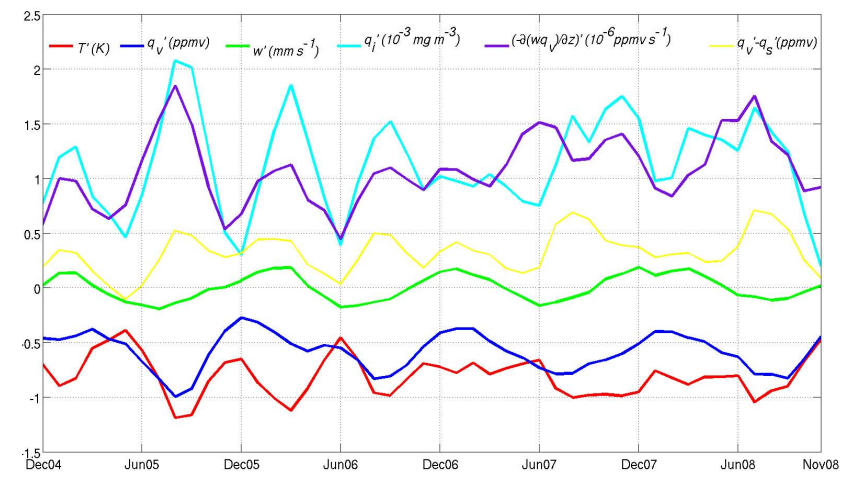

Fig. 6. The time series of monthly averaged differences between the WRF CTRL and UTNR simulations at $100 \mathrm{hPa}$. Temperature (K) difference in red; water vapor (ppmv) difference in blue; vertical velocity $\left(\mathrm{mm} \mathrm{s}^{-1}\right)$ difference in green; ice water content $\left(10^{-3} \mathrm{mg} \mathrm{m}^{-3}\right)$ in cyan; vertical water vapor flux $\left(\left(-\frac{\partial\left(w q_{v}\right)}{\partial z}\right)^{\prime}\right.$; $\left.10^{-6} \mathrm{ppmv} \mathrm{s}^{-1}\right)$ in purple; the difference between water vapor difference and saturation water vapor difference $\left(q_{v}^{\prime}-q_{s}^{\prime}\right.$; ppmv $)$ in yellow.

UTCRE induced monthly averaged differences at $100 \mathrm{hPa}$ (Fig. 6), the UTCRE induced cooling increases cloud formation in the TTL and the change of IWC agrees well with the temperature change (with a correlation of -0.81). However, the change of water vapor (from UTNR to CTRL) is not exactly in phase with that of temperature (with a correlation of 0.59). We calculate the saturation vapor pressure change at $100 \mathrm{hPa}$ based on the temperature change and compare that with the water vapor change $\left(q_{v}^{\prime}-q_{s}^{\prime}\right.$; yellow line in Fig. 6). We find that their difference follows the change of vertical water vapor flux $\left(\left(-\frac{\partial\left(w q_{v}\right)}{\partial z}\right)^{\prime}\right.$; purple line in Fig. 6) with a correlation of 0.58 . This suggests that vertical transport of water vapor induced by UTCRE increases water vapor at $100 \mathrm{hPa}$, partly compensating the freezing-drying associated with the decrease of temperature, resulting in a phase-shift between temperature and water vapor changes. It is obvious that simple thermodynamic energy balance is not sufficient to explain the temporal evolution of TTL water vapor change. Changes in the dynamic fields, such as vertical ascent, also play an important role.

Furthermore, the difference of the domain-averaged vertical velocity at $100 \mathrm{hPa}$ between the CTRL and UTNR runs changes sign from DJF to JJA (Fig. 6), despite of a persistent increase of UTCRE from the UTNR to the CTRL all year around. Considering the spatial inhomogeneities of UTCRE, it is possible that the vertical velocity changes induced by UTCRE are also horizontally non-uniform. Compensating subsidence associated with the radiatively induced vertical ascent may yield different response in the tropical-average at different seasons. These point to the need to examine spatial variations of the UTCRE as shown in Fig. 7.
The seasonal maps of the UTCRE induced differences at $100 \mathrm{hPa}$ are displayed in Fig. 7. In both DJF and JJA, UTCRE mainly enhances ascent (Fig. 7a and 7b) in cloudy regions (see Fig. 3c and d). UTCRE induces subsidence to the west of cloudy regions (Fig. 7a and b) due to wave response (Gill, 1980; Rodwell and Hoskins, 1996). In JJA, more intense downward motion is shown in the inner tropics than in DJF (Fig. 7b), which results in the domain-averaged reduction of vertical ascent at $100 \mathrm{hPa}$ in JJA (Fig. 6). Adiabatic cooling (warming) is associated with the UTCRE induced ascent (descent), with maximum cooling (warming) shifted to the west of the maximum ascent (descent) due to horizontal advection. Except over the Indian Ocean, dehydration by UTCRE corresponds to cooling in most regions, with maximum dehydration shown at the western Pacific around $20^{\circ} \mathrm{N}$ (Fig. 7c and d). Over the Indian Ocean, UTCRE induces strong westerly anomalies (weakening of easterly) in DJF and strong easterly anomalies in JJA. The strong wind anomalies carry dehydrated air downstream away from the origin that dehydration takes place, resulting in offsets of the locations of the driest and coldest anomalies. Thus, less dehydration (hydration around the descent in DJF) is shown over the Indian Ocean in both DJF and JJA although cold anomalies over the Indian Ocean are stronger than over western Pacific (Fig. 7a and b). Similarly, the increase of clouds is shifted away from the strongest negative temperature anomalies due to horizontal advection by anomalous winds (Fig. 7e and 7f). Less cloud increase occurs over the Indian Ocean comparing to western Pacific.

Hence, the argument is still valid at $100 \mathrm{hPa}$, where the enhanced updrafts in cloudy regions induce adiabatic cooling and dehydration in both DJF and JJA. However, strong descent anomaly to the west of ascent are induced by UTCRE at $100 \mathrm{hPa}$ (Fig. 7b), which leads to decrease of vertical velocity in JJA in the domain-averages (Fig. 5c and 6). The dehydration by adiabatic cooling is counteracted by the enhanced vertical transport of water vapor at $100 \mathrm{hPa}$, which results in that the magnitude of water vapor changes is not following the magnitude of temperature changes (Fig. 6). Due to significant changes of horizontal winds (mainly around Indian Ocean) induced by UTCRE, the maximum UTCRE induced cooling is not collocated with the maximum dehydration.

\section{Conclusion}

In this study, we implement the tropical channel configuration of the WRF model to investigate the radiative impacts of upper tropospheric clouds (all clouds above $200 \mathrm{hPa}$ ) on the TTL water vapor. The 4-yr WRF simulations show reasonable agreements with observations on CRE and water vapor in the TTL, including approximate reproduction of the water vapor "tape recorder" in the TTL.

Sensitivity experiment demonstrates that UTCRE increases temperature and vertical motion in the UT from 

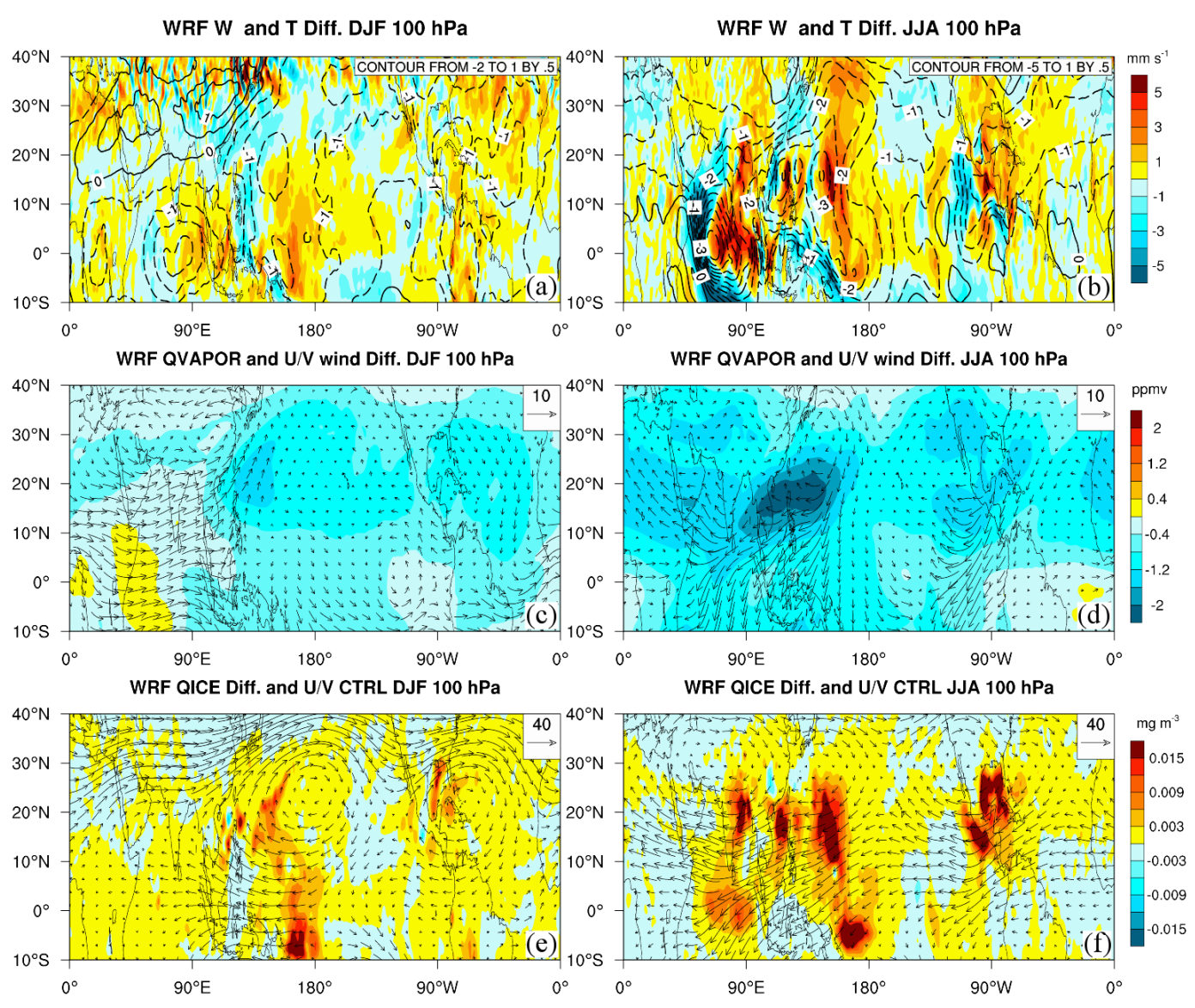

Fig. 7. (a) The differences of vertical velocity (shade; $\mathrm{mm} \mathrm{s}^{-1}$ ) and temperature (contour with dashed lines for negative values and solid lines for positive values; K) between the WRF CTRL and UTNR runs at $100 \mathrm{hPa}$ in DJF; (b) Same as (a) but in JJA; (c) The differences of water vapor (shade; ppmv) and horizontal wind (vector; $\mathrm{m} \mathrm{s}^{-1}$ ) between the WRF CTRL and UTNR runs at $100 \mathrm{hPa}$ in DJF; (d) Same as (c) but in JJA; (e) The horizontal wind (vector; $\mathrm{m} \mathrm{s}^{-1}$ ) in the WRF CTRL run and the difference of cloud ice (shade; $\mathrm{mg} \mathrm{m}^{-3}$ ) between the WRF CTRL and UTNR runs at $100 \mathrm{hPa}$ in DJF; (f) Same as (e) but in JJA.

$215 \mathrm{hPa}$ to $147 \mathrm{hPa}$. On the 4 -yr average at $215 \mathrm{hPa}$, UTCRE contributes to a warming of $0.76 \mathrm{~K}$ and enhanced updraft by $49 \%$ in the WRF CTRL run. The significant warming and enhanced vertical transport lead to increase of both water vapor (increase by $9 \%$ at $215 \mathrm{hPa}$ ) and clouds in the UT. In the lower TTL from $147 \mathrm{hPa}$ to $83 \mathrm{hPa}$, increase of upwelling by UTCRE contributes to enhanced vertical transport of water vapor. However, the enhanced vertical motion is associated with increased adiabatic cooling, which dehydrates the lower TTL by forming more ice clouds. The dehydration by adiabatic cooling offsets the hydration by the enhanced vertical transport and results in a net dehydration in the lower TTL. On the 4-yr average, the simulated UTCRE leads to a maximum cooling of $0.82 \mathrm{~K}$ and a maximum dehydration of $16 \%$ at $100 \mathrm{hPa}$. The cloud radiative cooling induces reduction of the ascent rate, temperature decrease and dehydration above $83 \mathrm{hPa}$.

On the 4-yr averaged vertical profiles in the inner tropics, the change of water vapor shows strong dependence on the temperature change. However, the change of water va- por is not in phase with the change of temperature due to the competing effect of enhanced vertical transport of water vapor by UTCRE. Moreover, the maps at $100 \mathrm{hPa}$ show that the maximum dehydration is not collocated with the maximum cooling. The UTCRE induced temperature change has substantial horizontal and vertical variations over the tropics. At $100 \mathrm{hPa}$, UTCRE generally induces ascent in cloudy regions and descent to the west of ascent. The UTCRE induced anomalous horizontal advection over Indian Ocean transports water vapor anomalies away from the lowest temperature anomalies. Due to horizontal advection, the maximum cooling is also located west of the maximum ascent anomaly in the tropics.

This study confirms that the radiative impacts of upper tropospheric clouds contribute substantially to tropical TST (Corti et al., 2005, 2006) and have significant impact on the dehydration in the TTL. UTCRE affects cirrus formation in the TTL. However, unlike the simple one-dimensional (or two column) perspective offered by Corti et al. (2005; 2006), the radiative effects of clouds show large horizontal 
inhomogeneity and temporal non-stationarity. This is largely due to the inhomogeneity of cloud distributions and compensating vertical motion in response to in-cloud radiative heating. Given that large-scale wave forcing governs the vertical ascent in the TTL on the first order, the effects of in-cloud radiative heating on tropical-averaged vertical velocity are $0.2 \%$ and $-16 \%$ on the tropical-mean water vapor amount at $100 \mathrm{hPa}$. However, their effects can be much larger locally. Thus, an accurate representation of UTCRE is needed in order to have a realistic water vapor distribution in the UTLS. Recent studies indicate aerosols may interact with UT clouds to affect TTL water vapor through radiative and microphysical processes (Su et al., 2011; Wu et al., 2011), further pointing to the importance of continued study of UTCRE on TTL mass transport.

Our analysis also shows that horizontal transport is quite important to dehydration in the TTL. It is insufficient to investigate dehydration simply based on temperature without consideration of the large-scale circulation. As pointed out by previous studies (Fueglistaler et al. 2005; Tzella and Legras, 2011), a representation of large-scale circulation is necessary to well quantify the dehydration processes in the TTL.

Some caveats in this study should be noted. First, the simulated water vapor "tape recorder" travels upward faster than the MLS observations, especially in the stratosphere. The stratospheric Brewer-Dobson circulation is one of the most important factors contributing to the "tape recorder" signal and transport in the stratosphere (Fueglistaler et al., 2009, and references therein). The simulated fast transport in the stratosphere might be due to the model top being $10 \mathrm{hPa}$, which cannot fully represent the Brewer-Dobson circulation. Secondly, in the inner tropics, the CERES data have larger cloud forcing in DJF than in JJA. Although the model simulation captures the distribution of TOA LWCF as in CERES, it produces larger cloud forcing in JJA than in DJF. Caution should be used when interpreting the seasonal variation and magnitude of UTCRE. Thirdly, much finer horizontal resolution may be needed to accurately capture the cloud formation and evolution and their impacts on the water vapor transport from the troposphere to the stratosphere. Lastly, because of the constraint of mass balance in the limited model domain (the imposed return flow in response to the enhanced upwelling in the convective regions dissipates in the relaxation zone near the lateral boundary), our results may not fully capture the cloud radiative effect in the entire tropics.

Acknowledgements. The authors thank Leonhard Pfister for valuable discussions. Comments from the editor Peter Haynes and two anonymous reviewers are appreciated. This study was supported by NASA Aura Science Team program, as well as the Aura MLS project. The work is conducted at the Jet Propulsion Laboratory, California Institute of Technology, under contract with NASA. The JPL author's copyright for this publication is held by the California Institute of Technology. Government Sponsorship acknowledged.
Edited by: P. Haynes

\section{References}

Brewer, A. W.: Evidence for a world circulation provided by the measurements of helium and water vapour distribution in the stratosphere, Q. J. R. Meteorol. Soc., 75, 351-363, 1949.

Chen, S.-H. and Sun, W.-Y.: A one-dimensional time dependent cloud model, J. Meteor. Soc. Jpn., 80, 99-118, 2002.

Chou M.-D. and Suarez, M. J.: An efficient thermal infrared radiation parameterization for use in general circulation models, NASA Tech. Memo. 104606, 3, 85 pp., 1994.

Corti, T., Luo, B. P., de Reus, M., Brunner, D., Cairo, F., Mahoney, M. J., Martucci, G., Matthey, R., Mitev, V., dos Santos, F. H., Schiller, C., Shur, G., Sitnikov, N. M., Spelten, N., Vössing, H. J., Borrmann, S., and Peter, T: Unprecedented evidence for deep convection hydrating the tropical stratosphere, Geophys. Res. Lett., 35, L10810, doi:10.1029/2008GL033641, 2008.

Corti, T., Luo, B. P., Peter, T., Vömel, H., and Fu, Q.: Mean radiative energy balance and vertical mass fluxes in the equatorial upper troposphere and lower stratosphere, Geophys. Res. Lett., 32, L06802, doi:10.1029/2004GL021889, 2005.

Corti, T., Luo, B. P., Fu, Q., Vömel, H., and Peter, T.: The impact of cirrus clouds on tropical troposphere-to-stratosphere transport, Atmos. Chem. Phys., 6, 2539-2547, doi:10.5194/acp-6-25392006, 2006.

Dinh, T. P., Durran, D. R., and Ackerman, T. P.: Maintenance of tropical tropopause layer cirrus, J. Geophys. Res., 115, D02104, doi:10.1029/2009JD012735, 2010.

Fueglistaler, S., Bonazzola, M., Haynes, P. H., and Peter, T.: Stratospheric water vapor predicted from the Lagrangian temperature history of air entering the stratosphere in the tropics, J. Geophys. Res., 110, D08107, doi:10.1029/2004JD005516, 2005.

Fueglistaler, S., Dessler, A. E., Dunkerton, T. J., Folkins, I., Fu, Q., and Mote, P. W.: Tropical tropopause layer, Rev. Geophys., 47, RG1004, doi:10.1029/2008RG000267, 2009.

Gill, A. E.: Some simple solutions for heat-induced tropical circulation, Q. J. Roy. Meteor. Soc., 106, 447-462, 1980.

Grell, G. A. and Dévényi, D.: A generalized approach to parameterizing convection combining ensemble and data assimilation techniques, Geophys. Res. Lett., 29, 1693, doi:10.1029/2002GL015311, 2002.

Hartmann, D. L., Holton, J. R., and Fu, Q.: The heat balance of the tropical tropopause, cirrus, and stratospheric dehydration, Geophys. Res. Lett., 28, 1969-1972, doi:10.1029/2000GL012833, 2001.

Holton, J. R. and Gettelman, A.: Horizontal transport and the dehydration of the stratosphere, Geophys. Res. Lett., 28, 2799-2802, 2001.

Huang, X. and Su, H.: Cloud radiative effect on tropical troposphere to stratosphere transport represented in a large-scale model, Geophys. Res. Lett., 35, L21806, doi:10.1029/2008GL035673, 2008.

Iacono, M. J., Mlawer, E. J., Clough, S. A., and Morcrette, J.-J.: Impact of an improved longwave radiation model, RRTM, on the energy budget and thermodynamic properties of the NCAR community climate model, CCM3, J. Geophys. Res., 105, 1487314890, doi:10.1029/2000JD900091, 2000.

Jensen, E. and Pfister, L.: Transport and freeze-drying in the tropical tropopause layer, J. Geophys. Res., 109, D02207, 
doi:10.1029/2003JD004022, 2004.

Jensen, E. J., Toon, O. B., Pfister, L., and Selkirk, H. B.: Dehydration of the upper troposphere and lower stratosphere by subvisible cirrus clouds near the tropical tropopause, Geophys. Res. Lett., 23, 825-828, doi:10.1029/96GL00722, 1996.

Jiang, J. H., Su, H., Pawson, S., Liu, H. C., Read, W., Waters, J. W., Santee, M., Wu, D. L., Schwartz, M., Livesey, N., Lambert, A., Fuller, R., and Lee, J. N.: Five-year (2004-2009) Observations of Upper Tropospheric Water Vapor and Cloud Ice from MLS and Comparisons with GEOS-5 analyses, J. Geophys. Res., 115, D15103, doi:10.1029/2009JD013256, 2010.

Livesey, N. J., Read, W. G., Froidevaux, L., Lambert, A., Manney, G. L., Pumphrey, H. C., Santee, M .L., Schwartz, M. J., Wang, S., Cofield, R. E., Cuddy, D. T., Fuller, R A., Jarnot, R. F., Jiang, J. H., Knosp, B. W., Stek, P. C., Wagner, P. A., and Wu, D. L.: EOS Aura Microwave Limb Sounder Version 3.3 Level 2 data quality and description document. JPL document D-33509, 2011.

Mlawer, E. J., Taubman, S. J., Brown, P. D., Iacono, M. J., and Clough, S. A.: Radiative transfer for inhomogeneous atmosphere: RRTM, a validated correlated-k model for the longwave, J. Geophys. Res., 102, 16663-16682, 1997.

Mote, P., Dunkerton, T., Mclntyre, M., Ray, E., Haynes, P., and Russell III, J.: Vertical velocity, vertical diffusion, and dilution by midlatitude air in the tropical lower stratosphere, J. Geophys. Res., 103, 8651-8666, 1998.

Mote, P., Rosenlof, K., Mclntyre, M., Carr, E., Gille, J., Holton, J., Kinnersley, J., Pumphrey, H., Russell III, J., and Waters, J.: An atmospheric tape recorder: The imprint of tropical tropopause temperatures on stratospheric water vapor, J. Geophys. Res., 101, 3989-4006, 1996.

Newell, R. E. and Gould-Stewart, S.: A Stratospheric Fountain?, J. Atmos. Sci., 38, 2789-2796, 1981.

Ray, P. and Zhang, C. D.: A Case Study of the Mechanics of Extratropical Influence on the Initiation of the Madden-Julian Oscillation. J. Atmos. Sci., 67, 515-528, doi:10.1175/2009JAS3059.1, 2010.

Ray, P., Zhang, C., Moncrieff, M. W., Dudhia, J., Caron, J. M., Leung, L. R., and Bruyere, C.: Role of the atmospheric mean state on the initiation of the MJO in a tropical channel model, Climate Dynam., 36, 161-184, 2011.

Read, W. G., Lambert, A., Bacmeister, J., Cofield, R. E., Christensen, L. E., Cuddy, D. T., Daffer, W. H., Drouin, B. J., Fetzer, E., Froidevaux, L., Fuller, R., Herman, R., Jarnot, R. F., Jiang, J. H., Jiang, Y. B., Kelly, K., Knosp, B. W., Kovalenko, L. J., Livesey, N. J., Liu, H.-C., Manney, G. L.,Pickett, H. M., Pumphrey, H. C., Rosenlof, K. H., Sabounchi, X., Santee, M. L.,Schwartz, M. J., Snyder, W. V., Stek, P. C., Su, H., Takacs, L. L., Thurstans, R. P., Vömel, H., Wagner, P. A., Waters, J. W.,Webster, C. R., Weinstock, E. M., and Wu, D. L: Aura Microwave Limb Sounder upper tropospheric and lower stratospheric $\mathrm{H}_{2} \mathrm{O}$ and relative humidity with respect to ice validation, J. Geophys. Res., 112, D24S35, doi:10.1029/2007JD008752, 2007.
Rodwell, M. J. and Hoskins, B. J.: Monsoons and the dynamics of deserts, Q. J. Roy. Meteor. Soc., 122, 1385-1404, 1996.

Rosenfield, J. E., Considine, D. B., Schoeberl, M. R., and Browell, E. V.: The impact of subvisible cirrus clouds near the tropical tropopause on stratospheric water vapor, Geophys. Res. Lett., 25, 1883-1886, doi:10.1029/98GL01294, 1998.

Schoeberl, M. R. and Dessler, A. E.: Dehydration of the stratosphere, Atmos. Chem. Phys., 11, 8433-8446, doi:10.5194/acp11-8433-2011, 2011.

Sherwood, S. C. and Dessler, A. E.: On the control of stratospheric humidity, Geophys. Res. Lett., 27, 2513-2516, 2000.

Sherwood, S. C. and A. E. Dessler (2003), Convective Mixing near the Tropical Tropopause: Insights from Seasonal Variations, J. Atmos. Sci., 60, 2674-2685.

Skamarock, W. C., Klemp, J. B., Dudhia, J., Gill, D. O., Barker, D. M., Wang, W., and Powers, J. G.: A Description of the Advanced Research WRF Version 3, NCAR Technical Note TN-468+STR, 113 pp., 2008.

Su, H., Jiang, J. H., Stephens, G. L., Vane, D. G., and Livesey, N. J.: Radiative effects of upper tropospheric clouds observed by Aura MLS and CloudSat, Geophys. Res. Lett., 36, L09815, doi:10.1029/2009GL037173, 2009.

Su, H., Jiang, J. H., Liu, X., Penner, J. E., Read, W. G., Massie, S.,Schoeberl, M. R., Colarco, P., Livesey, N. J., and Santee, M. L.: Observed increase of TTL temperature and water vapor in polluted clouds over Asia, J. Climate, 24, 2728-2736, doi:10.1175/2010JCLI3749.1, 2011.

Tzella, A. and Legras, B.: A Lagrangian view of convective sources for transport of air across the Tropical Tropopause Layer: distribution, times and the radiative influence of clouds, Atmos. Chem. Phys., 11, 12517-12534, doi:10.5194/acp-11-12517-2011, 2011.

Waters, J. W., Froidevaux, L., Harwood, R. S., Jarnot, R. F., Pickett, H. M., Read, W. G., Siegel, P. H., Cofield, R. E., Filipiak, M. J., Flower, D. A., Holden, J. R., Lau, G. K., Livesey, N. J., Manney, G. L., Pumphrey, H. C., Santee, M. L., Wu, D. L., Cuddy, D. T., Lay, R. R., Loo, M. S., Perun, V. S., Schwartz, M. J., Stek, P. C., Thurstans, R. P., Boyles, M. A., Chandra, K. M., Chavez, M. C., Chen, G.-S., Chudasama, B. V., Dodge, R., Fuller, R. A., Girard, M. A., Jiang, J. H., Jiang, Y., Knosp, B. W., Labelle, R. C., Lam, J. C., Lee, A. K., Miller, D., Oswald, J. E., Patel, N. C., Pukala, D. M., Quintero, O., Scaff, D. M., Vansnyder, W., Tope, M. C., Wagner, P. A., and Walch, M. J.: The Earth Observing System Microwave Limb Sounder (EOS MLS) on the Aura satellite, IEEE Trans. Geosci. Remote Sens., 44, 1075-1092, doi:10.1109/TGRS.2006.873771, 2006.

Wu, L., Su, H., and Jiang, J. H.: Regional simulations of deep convection and biomass burning over South America: 2. Biomass burning aerosol effects on clouds and precipitation, J. Geophys. Res., 116, D17209, doi:10.1029/2011JD016106, 2011.

Yang, Q., Q. Fu, and Hu, Y.: Radiative impacts of clouds in the tropical tropopause layer, J. Geophys. Res., 115, D00H12, doi:10.1029/2009JD012393, 2010. 